\title{
Bilangan Ramsey untuk Graf Bintang Genap Terhadap Roda Genap
}

\author{
Hasmawati*
}

\begin{abstract}
Abstrak
Untuk sebarang graf $G$ dan $H$, bilangan Ramsey $R(G, H)$ adalah bilangan asli terkecil $n$ sedemikian sehingga sebarang graf $F$ yang berorde $n$ memenuhi kondisi berikut: $F$ memuat $G$ atau komplemen $F$ memuat $H$. Dalam makalah ini dikaji bilangan Ramsey $R(G, H)$, dimana $G$ adalah graf bintang $S_{n}$ dan $H$ adalah graf roda $W_{m}$. Kami akan menunjukkan bahwa $R\left(S_{4}, W_{6}\right.$ )=9 dan untuk $n=6,8$, maka $R\left(S_{n}, W_{m}\right)=2 n+1$ untuk $m=n$.
\end{abstract}

Kata Kunci: Bilangan Ramsey, Graf Bintang, Graf Roda.

\begin{abstract}
For given graphs $G$ dan $H$, the Ramsey number $R(G, H)$ is the smallest natural number $n$ such that for every graph $F$ of order n: either $F$ contains $G$ or the complement of $F$ contains $H$. This paper investigates the Ramsey numbers $R(G, H)$, where $G$ is a stars $S_{n}$ and $H$ is wheels $W_{m}$. We show that $R\left(S_{4}, W_{6}\right)=9$ and for $n=4,6,8$ then $R\left(S_{n}, W_{m}\right)=2 n+1$ for $m=n$.
\end{abstract}

Keywords: Ramsey Number, Star Graph, Wheel Graph.

\section{Pendahuluan}

Graf $G(V, E)$ adalah suatu sistem yang terdiri dari himpunan titik berhingga tak kosong $V=V(G)$ dan himpunan sisi $E=E(G)$ yaitu himpunan pasangan tak terurut dari anggota-anggota $V$. Jika $V(G)$ mempunyai anggota sebanyak $n$, maka graf $G$ dikatakan berorde $n$ dan dinotasikan $|G|=n$. Jika $u, v \in V(G)$ dan $e=u v \in E(G)$, maka $u$ disebut tetangga dari $v$, demikian pula sebaliknya.

Graf $G$ dengan $n$ titik dan setiap dua titiknya bertetangga disebut graf lengkap, dinotasikan dengan $K_{n}$. Graf $F$ disebut komplemen dari graf $G$ bila $V(F)=V(G)$ dan $u v \in E(F)$ jika dan hanya jika $u v \notin E(G)$. Komplemen dari graf $G$ dinotasikan dengan $\bar{G}$. Graf $H$ disebut subgraf dari $G$ jika $V(H) \subseteq V(G)$ dan $E(H) \subseteq E(G)$. Himpunan titik $V$ pada graf $G$ disebut himpunan titik bebas jika setiap dua titik di $V$ tidak bertetangga. Notasi $\alpha_{0}(G)$ menyatakan banyaknya titik pada himpunan titik bebas maksimal di $G$. Suatu graf $G$ dikatakan bipartit jika $V(G)$ dapat dipartisi kedalam dua subhimpunan tak kosong $V_{1}$ dan $V_{2}$, sedemikian sehingga untuk setiap sisi $e=u v \in E(G)$, berlaku $u \in V_{1}$ dan $v \in V_{2}$ atau $v \in V_{1}$ dan $u \in V_{2}$. Misalkan $G$ adalah graf bipartit dengan $\left|V_{1}\right|=n$ dan $\left|V_{2}\right|=m$. Graf $G$ dikatakan bipartit lengkap dan dinotasikan $K_{n, m}$, jika setiap titik $u \in V_{1}$ dan $v \in V_{2}$ terdapat sisi $e=\mathrm{uv} \in E(G)$.

Misalkan $G_{1}$ adalah graf dengan himpunan titik $V_{1}$ dan himpunan sisi $E_{1}$, serta $G_{2}$ adalah graf dengan himpunan titik $V_{2}$ dan himpunan sisi $E_{2}$, graf gabungan $G=G_{1}+G_{2}$ adalah graf

\footnotetext{
* Jurusan Matematika FMIPA Universitas Hasanuddin Makassar
} 
dengan himpunan titik $V(G)=V_{1} \cup V_{2}$ dan himpunan sisi $E(G)=E_{1} \cup \mathrm{E}_{2} \cup\left\{u v: u \in V_{1}, v \in\right.$ $\mathrm{V}_{2}$ \}. Misalkan $G$ adalah suatu graf dengan himpunan titik $V(G)=v_{1}, v_{2}, \ldots, v_{n}$ dan $x=v_{i} v_{j} \notin E(G)$ untuk suatu $i, j \in\{1,2, \ldots, n\}$. Graf $G^{\prime}:=G+x$ adalah suatu graf baru dengan himpunan titik $V\left(G^{\prime}\right)=V(G)$ dan himpunan sisi $E\left(G^{\prime}\right)=E(G) \cup\{x\}$.

Jalan dari $u$ ke $v$ dengan panjang $k$ pada graf $G(V, E)$ adalah suatu subgraf dengan barisan titik $u=u_{0}, u_{1}, \ldots, u_{k}$ dimana $\left(u_{1} u_{i+1}\right) \in E(\mathrm{G})$ untuk $i=1,2, \ldots, k-1$. Lintasan $P_{n}$ adalah jalan dengan $n$ titik yang setiap titiknya berbeda. Suatu graf dikatakan terhubung jika untuk setiap dua titik $u$ dan $v$ dari graf tersebut terdapat suatu lintasan dari u ke v. Komponen dari suatu graf adalah subgraf terhubung maksimal dari graf tersebut. Jika $P_{n}$ adalah suatu lintasan dengan barisan titik $v_{1}, v_{2}, \ldots$, $v_{n}$ dan $n \geq 3$. maka graf $C_{n}:=P_{n}+v_{l} v_{n}$ disebut siklus dengan $n$ titik. Graf pohon $T_{n}$ (tree) adalah graf terhubung dengan $n$ titik yang tidak memuat siklus. Graf roda $W_{k}$ (wheel) dengan $k+1$ titik adalah graf $C_{k}+K_{1}$. Titik $x \in V\left(K_{1}\right)$ disebut titik pusat roda (hub) dan siklus $C_{k}$ disebut rim dari roda. Graf $\overline{K_{n-1}}+K_{1}$ disebut graf bintang (star) dengan $n$ titik, dan dinotasikan $S_{n}$. Titik $x \in$ $V\left(K_{1}\right)$ disebut sebagai titik pusat (center) graf bintang (Gambar 1).

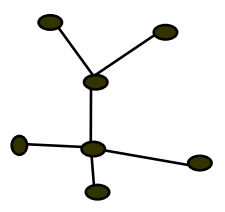

a) $T_{7}$

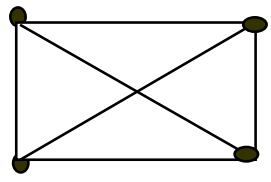

c) $K_{4}$

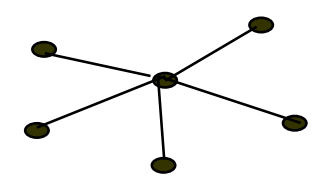

b) $S_{6}$

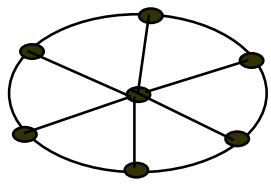

d) $W_{6}$

Gambar 1. a) graf pohon, b) graf bintang, c) graf lengkap, dan d) graf roda.

Panjang siklus terbesar pada suatu graf $G$ dinotasikan dengan $c(G)$, sedangkan panjang siklus terkecil dinotasikan dengan $g(G)$. Graf $G$ dengan orde $n$ disebut pancyklic jika $G$ memuat semua siklus $C_{l}$ dengan $3 \leq l \leq n$, dan disebut pancyklic lema jika $G$ memuat $C_{h}$ dengan $g(G) \leq h$ $\leq c(G)$. Misalkan $G(V, E)$ adalah sebarang graf sederhana dan $k$ adalah sebarang bilangan asli. Graf $G$ disebut terhubung- $k$ jika $|G|>k$ dan $G$-X terhubung untuk setiap $X \subseteq V \cup E$ dengan $|X|<k$. Keterhubungan $\kappa(G)=k$ adalah bilangan bulat terbesar $k$ sehingga $G$ merupakan graf terhubung- $k$. Berikut ini disajikan tiga lema dimana ketiga lema ini digunakan dalam pembuktian hasil-hasil pada penelitian ini.

\section{Lemma 1. (Lemma Bondy)}

Misalkan $G$ adalah graf berorde $n$. Jika $\delta(G) \geq \frac{n}{2}$, maka $G$ adalah pansiklis atau $K_{\frac{n}{2}, \frac{n}{2}}$ untuk $n$ genap. 
Bilangan Ramsey $R(G, H)$ untuk sebarang graf $G$ dan graf $H$ adalah bilangan asli terkecil $n$ sedemikian sehingga untuk setiap graf $F$ dengan $n$ titik memenuhi kondisi: $F$ memuat $G$ atau $\bar{F}$ memuat $H$. Misalkan $F$ berorde $n$ tidak memuat $G$ dan $\bar{F}$ tidak memuat $H$. Jika sebarang graf dengan orde $n+1$ senantiasa memuat $G$ atau komplemennya memuat $H$, maka $F$ disebut graf kritis untuk $G$ dan $H$. Bilangan kromatik $\chi(H)$ adalah bilangan asli terkecil $k$ sehingga jika titiktitik pada $H$ dapat diwarnai dengan $k$ warna maka setiap dua titik yang bertetangga pada $H$ mempunyai warna berbeda. Chvatal dan Harary (1972) memberikan batas bawah untuk $R(G, H)$, yaitu $R(G, H) \geq(\chi(H)-1)(c(G)-1)+1$, dimana $c(G)$ adalah banyaknya titik pada komponen terbesar $G$. Berdasarkan batas bawah Chvatal dan Harary ini diperoleh:

- Batas bawah untuk $R\left(S_{n}, W_{m}\right)$ dimana $n \geq 3$ dan $m$ ganjil adalah $3 n-2$.

- Batas bawah untuk $R\left(S_{n}, W_{m}\right)$ dimana $n \geq 3$ dan $m$ genap adalah $2 n-1$.

- Batas bawah untuk $R\left(T_{n}, K_{m}\right)$ dimana $n$ dan $m$ sembarang adalah $(m-1)(n-1)+1$.

Beberapa bilangan Ramsey yang telah dihasilkan antara lain dalam Burr et al. (1975) yang membuktikan bahwa $k m+l \mathrm{n}-\min (m i, n j)-1 \leq R(m G, n H) \leq k m+l n-m i n(m i, n j)+C$, dimana $|G|=k,|H|=l, i=\alpha_{0}(G)$ dan $j=\alpha_{0}(H)$. Dalam Baskoro (2002) telah dibuktikan bahwa jika $n \geq 3$, maka $R\left(S_{n}, W_{5}\right)=3 n-2$. Chen et al. menunjukkan bahwa jika $n \geq m-1 \geq 2$ dan m ganjil maka $R\left(S_{n}, W_{m}\right)=3 n-2$. Dalam Hasmawati (2004) diperoleh $R\left(S_{n}, W_{m}\right)=m+n-2$ untuk $n$ ganjil dan $m$ genap, $R\left(S_{n}, W_{m}\right)=m+n-1$ untuk yang lainnya.

Dalam Korolova (2004) diperoleh hasil yang lebih baik untuk bintang genap terhadap roda genap. Hasilnya dituliskan dalam teorema berikut.

\section{Teorema 1.}

Jika $m$ genap dan $m \leq n$, maka $R\left(S_{n}, W_{m}\right) \geq 2 n-1$.

\section{Hasil Utama}

Pasal ini menyajikan dua hasil utama yang dituliskan dalam bentuk teorema. Penyajian teorema langsung disertai dengan bukti.

Teorema 2. $R\left(S_{4}, W_{6}\right)=9$.

\section{Bukti:}

Pandang graf $\bar{F}=\bar{K}_{3}+C_{5}$. Graf ini berorde 8 dan tidak memuat $W_{6}$. Sedangkan graf $F$ adalah graf 2-reguler yang berarti tidak memuat $S_{4}$. Jadi graf $F$ adalah graf kritis untuk $S_{4}$ dan $W_{6}$. Dengan demikian diperoleh $R\left(S_{4}, W_{6}\right) \geq 9$. 


\section{Hasmawati}

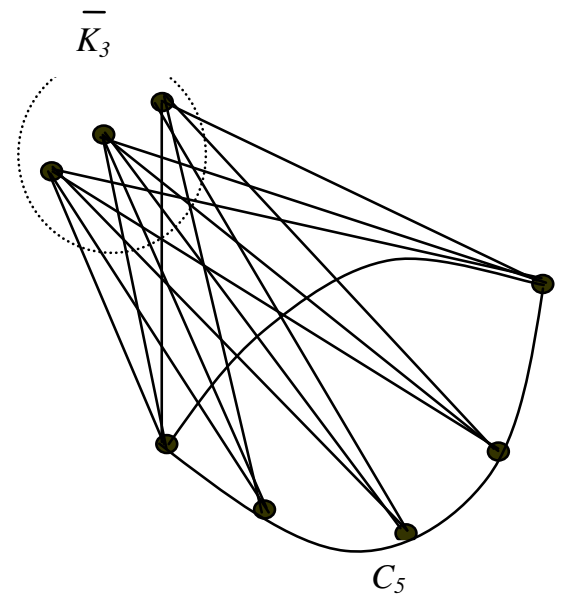

Gambar 2. Graf $\bar{F}=\bar{K}_{3}+C_{5}$.

Berikutnya akan ditunjukkan bahwa bilangan Ramsey $R\left(S_{4}, W_{6}\right) \leq 9$. Ambil sebarang graf $F_{1}$ dengan $\left|F_{1}\right|=9$. Andaikan $F_{1}$ tidak memuat $S_{4}$. Akan ditunjukkan $\bar{F}_{1}$ memuat $W_{6}$. Karena $F_{1}$ tidak memuat $S_{4}$ maka untuk setiap titik di $F_{1}$ mempunyai derajat paling tinggi 2. Ambil sembarang titik di $F_{1}$ sebut $x$. Tulis $A=V\left(F_{1}\right) \backslash N[x]$ dan $T$ adalah subgraf $F_{1}$ yang diinduksi oleh $A$. Berarti $|T|=A=\left|V\left(F_{1}\right)\right|-|N[x]|=9-3=6$ dan setiap titik $\bar{T}$ berderajat $|T|-3 \geq 3$. Nilai ini lebih besar atau sama dengan $\frac{|\bar{T}|}{2}$ menurut Lemma $1 \quad \bar{T}$ memuat semua siklus $C_{l}$ dengan $l=3,4,5$, dan 6. Berarti $\bar{T}$ memuat $C_{6}$. Titik $x$ bersama-sama $C_{6}$ membentuk $W_{6}$ di $\bar{F}_{1}$. Jadi diperoleh $F_{1}$ memuat $S_{4}$ atau $\bar{F}_{1}$ memuat $W_{6}$. Karenanya diperoleh $R\left(S_{4} W_{6}\right) \leq 9$. Dari kedua ketidaksamaan di atas disimpulkan $R\left(\mathrm{~S}_{4}, \mathrm{~W}_{6}\right)=9$.

\section{Teorema 2.}

$R\left(S_{n}, W_{m}\right)=2 n+1$ untuk $m=n$ dengan $n$ genap dan $n>4$.

\section{Bukti:}

Pandang $F$ dengan graf $|F|=2 n$. Bagi himpunan titik $V(F)$ kedalam dua kelompok sebut $A$ dan $B$. Labeli titik di $A$ dengan $a_{1}, a_{2}, \ldots, a_{2 k-1}$ dan titik-titik di $B$ dengan $b_{1}, b_{2}, \ldots, b_{2 \mathrm{k}+1}$ dengan $n=2 k$. Subgraf dari $F$ yang diinduksi oleh A $(F[A])$ isomorf dengan $K_{2 k-1}$ dan subgraf dari $F$ ( $F[B]$ ) yang diinduksi oleh B $(F[B])$, komplemennya isomorf dengan siklus $C_{2 k+1}$. Berarti $F[B]$ adalah subgraf yang setiap titiknya berderajat $2 k-2=n-2$. Ini artinya graf $F$ adalah graf ( $n$ 2)-reguler dan terdiri dari dua komponen. Dengan demikian $F$ tidak memuat $S_{n}$ untuk $n=6,8$. Mudah diperiksa bahwa $\bar{F}=\bar{K}_{n-1}+C_{n+1}$ untuk $n=6$, 8. Jadi Graf $\bar{F}$ memuat $W_{n+1}$ tetapi tidak memuat $W_{n}$. Jadi graf $F$ adalah graf kritis untuk $S_{\text {n }}$ dan $W_{m}$ untuk $n=m$. Dengan demikian diperoleh $R\left(S_{n}, W_{m}\right) \geq 2 n+1$ untuk $n=m$. 


\section{Hasmawati}

Berikutnya akan ditunjukkan bahwa bilangan Ramsey $R\left(S_{n}, W_{m}\right) \leq 2 n+1$. Ambil sebarang graf $F_{1}$ dengan $\left|F_{1}\right|=2 n+1$. Andaikan $F_{1}$ tidak memuat $S_{n}$. Akan ditunjukkan $\bar{F}_{1}$ memuat $W_{m}$. Karena $\quad F_{1}$ tidak memuat $S_{n}$ maka untuk setiap titik di $F_{1}$ mempunyai derajat paling besar $n$-2. Ambil sembarang titik di $F_{1}$ sebut $x$. Tulis $A=V\left(F_{1}\right) \backslash N[x]$ dan $T$ adalah subgraf $F_{1}$ yang diinduksi oleh $A$. Berarti $|T| \geq\left|V\left(F_{1}\right)\right|-|N[x]|=2 n+1-(n-2+1)=n+2$ dan setiap titik $\bar{T}$ berderajat $|T|-(n-3) \geq 3$. Untuk $n=6$, nilai ini lebih besar atau sama dengan $\frac{|\bar{T}|}{2}$ menurut Lemma $1 \bar{T}$ memuat semua siklus $C_{l}$ dengan $l=3,4,5$, dan 6 . Berarti $\bar{T}$ memuat $C_{6}$. Titik $x$ bersama-sama $C_{6}$ membentuk $W_{6}$ di $\bar{F}_{1}$. Jadi diperoleh $F_{1}$ memuat $S_{6}$ atau $\bar{F}_{1}$ memuat $W_{6}$. Karenanya diperoleh $R\left(S_{n} W_{m}\right) \leq 2 n+1$. Untuk $n=8$, nilai ini lebih kecil dari $\frac{|\bar{T}|}{2}$. Karena itu Lemma Bondy tidak dapat digunakan.

\section{Kesimpulan}

Bilangan Ramsey untuk kombinasi graf bintang dan graf roda $R\left(S_{n}, W_{m}\right)$ dengan $n$ genap dan $n<8$, Lemma Bondy masih dapat dimanfaatkan. Namun untuk $n \geq 8$, Lemma bondy tidak dapat lagi digunakan. Perlu syarat cukup atau syarat perlu yang lain yang dapat digunakan dalam pembuktiannya.

\section{Daftar Pustaka}

[1] Baskoro, E. T., Surahmat, Nababan, S. M. dan Miller, M., 2002, On Ramsey Numbers for Tree versus Wheels of Five or Six vertices, Graph Combin., 18: 717-721.

[2] Burr, S. A., Erdos, P., dan Spencer, J. H., 1975, Ramsey numbers for multiple copies of graphs, Trans. Amer. Math. Soc., 2009.

[3] Chen, Y. J., Zhang, Y. Q., dan Zhang, K. M., The Ramsey Number of Stars versus Whells, Discrete Math., to appear.

[4] Chvatal, V., Harary, F., 1972, Generalized Ramsey Theory for Graph, III:Small offDiagonal Numbers, Pac. J. Math., 41, 335-345.

[5] Hasmawati, 2004, Bilangan Ramsey untuk kombinasi Graf Bintang terhadap Graf Roda, Tesis Magister, Departemen Matematika ITB.

[6] Korolova, A., 2004, Ramsey Numbers of versus Whell of similar sizes, Discrete Math., $292,107-117$. 